\title{
ĐÁNH GIÁ KẾT QUẢ PHẪU THUÂTT ĐÎ̀̂U TRỊ ĐỤC THỂ THỦY TINH NHÂN NÂU ĐEN BẰNG PHƯƠ'NG PHÁP PHACO QUA ĐƯỜNG RACH GIÁC MẠC 2,2MM
}

\author{
Nguyễn Thị Phương Thảo ${ }^{1}$, Nguyễn Mạnh Đạt ${ }^{2}$, Cung Hồng Sơn ${ }^{3}$
}

TÓM TẮT

Mục tiêu: Đánh giá kết quả phẫu thuật và nhận xét vế đặc điểm kỹ thuật của phẩu thuật Phaco với nhân nâu đen qua đường rạch giác mạc $2,2 \mathrm{~mm}$. Đối tượng và phương pháp: Nghiền cứu mô tả tiến cứu trên 34 mắt của 26 bệnh nhân có thể thủy tinh đực đô IV và $V$ điều trị bằng phẫu thuật Phaco. Ghi nhận vể thị lực, sự thay đổi loạn thị trước và sau phấu thuật, độ loạn thị gây ra do phẫu thuật, những khó khăn và biến chứng trong và sau phẫu thuật. Kết quả: Thi lực trước mổ của bệnh nhân trong nhóm nghiên cứu đều thấp hơn ĐNT $5 \mathrm{~m}$. Một tháng sau mổ thị lực nhìn xa không chỉnh kính: có $50 \%$ số mắt có thị lực > 20/30, có $38,2 \%$ số mắt có thị lực từ $20 / 70-20 / 30$, không có trường hợp nào có thị lực < 20/200. Ở thời điểm 3 tháng đánh giá sự thay đổi loạn thị sau phẫu thuât thấy có $55,9 \%$ mắt có độ loạn thi tăng, 35,3\% số mắt có độ loạn thi giảm và $8,8 \%$ số mắt có độ loạn thị không thay đổi. Loạn thị trung bình gây ra do phấu thuật ở thời điểm 1 tuần là $0,2 \pm 0,11 \mathrm{D}$, sau 1 tháng là $0,18 \pm 0,06 \mathrm{D}$, sau 3 tháng là $0,17 \pm 0,09 \mathrm{D}$. Biến chứng trong và sau phẫu thuật ít, không gây ảnh hưởng lớn tới thị lực sau mổ. Kêt luận: Phâuu thuật Phaco nhân nâu đen qua đường rạch giác mạc $2.2 \mathrm{~mm}$ là phương pháp an toàn, hiệu quả, tỷ lệ thành công của phẩu thuật cao, đô loạn thị gây ra do phẫu thuật thẩp.

Tư khóa: nhẩn nâu đen, phẫu thuật phaco đường rạch 2,2mm

\section{SUMMARY \\ RESULTS OF PHACOEMULSIFICATION SURGERY THROUGH A 2.2 MM MICROINCISION IN HARD CARTARACTS}

Objective: to evaluate the results and some technical characteristics of phacoemulsification surgery through a $2.2 \mathrm{~mm}$ microincision in hard cataracts. Patients and methods: This is a prospective, description study on 34 eyes of 26 patients with hard cataract (Grade $\geq 4$ ) having undergone phacoemulsification. The variables included distance visual acuity (DVA), astigmatism induced by surgery and complications, intra - operative and postoperative complications. Results: The preoperative DVA of all 34 eyes were counting finger. After 1 month, 50\% had DVA of better than 20/30,

${ }^{1}$ Đại họ Y Hà Nôi

${ }^{2} B V$ măt tinh Hà Nam

${ }^{3} B V$ Mắt Trung Ương

Chịu trách nhiệm chính: Nguyễn Thị Phương Thảo

Email: nguyenthaovnio@gmail.com

Ngày nhận bài: 4.01 .2021

Ngày phản biện khoa học: 4.3.2021

Ngày duyệt bài: 15.3.20211
$38.2 \%$ had DVA from $20 / 70$ to $20 / 30$ and no eye had DVA worse than 20/200. 3 months after surgery, astigmatism increased in $55.9 \%$, decreased in $35.3 \%$ and was stable in $8.8 \%$ of cases. The mean of astigmatism induced by surgery after 1 week, 1 month and 3 months were 0,20 $\pm 0,11 \mathrm{D}, 0,18 \pm 0,06 \mathrm{D}, 0,17$ $\pm 0,09 \mathrm{D}$ respectively. There were few intra- operative and postoperative complications and they didn't affect the post-operative DVA. Conclusion: The phacoemulsification surgery through a $2.2 \mathrm{~mm}$ microincision in hard cataract is safe, effective with high success rate. The astigmatism induced by surgery is relatively low.

Key words: hard cataract, 2.2 corneal incision.

\section{I. ĐĂT VẤN ĐỀ}

Phẫu thuật Phaco điều trị đục thể thủy tinh đã trở nên phổ biến trên toàn thế giới với việc tán nhuyễn và lấy thể thủy tinh ngoài bao bằng siêu âm qua đường mổ nhỏ, thị lực phục hồi nhanh và hậu phẫu đơn giản so với các phương pháp khác. Phương pháp Phaco làm thuận lợi trên những mắt có nhân cứng vừa phải độ II, III nhưng làm phương pháp này với nhân nâu đen (độ IV, V) thì gặp phải những khó khăn nhất định như dễ toạc bao khi xé, chẻ và tán nhân khó hơn, phải dùng năng lượng phaco cao, thời gian phaco kéo dài... dễ dẫn tới nhiều biến chứng trong và sau mổ. ${ }^{1}$ Để làm rõ tính hiệu quả và an toàn của phương pháp phaco với nhẩn nâu đen dùng đường rạch giác mạc $2,2 \mathrm{~mm}$ chúng tôi tiến hành đề tài: "Đánh giá kêt quả phẫu thuật điều trị đực thể thửy tinh nhân nâu đen bằng phương pháp Phaco qua đường rạch giác mạc 2,2mm" với hai mục tiêu:

1. Đánh giá kêt quả phẫu thuật điều trị đục thể thưy tinh nhân nâu đen bằng phương pháp Phaco qua đường rạch giác mạc 2,2mm.

2. Nhận xét về đặc điểm kỹ thuật của phẫu thuật phaco với nhân nâu đen qua đường rạch giác mạc 2,2mm.

\section{II. ĐỐI TƯợNG VÀ PHƯƠNG PHÁP NGHIÊN CỨU}

Nghiên cứu mô tả tiến cứu được tiên hành tại khoa Đáy mắt-Màng bồ đào - bệnh viện Mắt TW trong thời gian từ tháng 1-2015 đến tháng 8-2015. Nghiên cứu bao gồm 34 mắt của 26 bệnh nhân được chẩn đoán đục thể thủy tinh tuổi già từ độ IV đến độ $V$ được phẫu thuật lấy thể thủy tinh bằng phương pháp phaco đặt thể 
thủy tinh nhân tạo (IOL - intraocular lens). Bênh nhân đồng ý tham gia nghiên cứu. Có khả năng theo dõi tái khám.

\section{KẾT QUẢ NGHIÊN CỨU VÀ BÀN LUÂN}

Đặc điểm bênh nhân. Trong nghiên cứu của chúng tôi tuổi trung bình của bệnh nhân là $71,6 \pm 12,3$ tuổi. Bệnh nhân có tuổi thấp nhất là 41 tuổi và cao nhất là 88 tuổi. Số bệnh nhân trong độ tuổi > 70 tuổi chiếm tỉ lệ cao nhất $(53,8 \%)$. Tuổi này phù hợp với độ tuổi trung bình trong các nghiên cứu của các tác giả Việt Nam như Đinh Thị Phương Thủy² 72,6 tuổi hay
Nguyễn Đỗ Nguyên ${ }^{3} 71,1$ tuổi và cũng tương tự như của tác giả Ilavska 70 tuổi. Tỉ lệ nữ: nam $\approx 4$ có thể là do tuổi thọ của bệnh nhân nữ cao hơn nam hoặc cũng có thể là ở Việt Nam những bênh nhân nữ ít được quan tâm tới sức khỏe hơn thường chỉ đi khám và điều trị khi thị lực giảm rất nhiều do thể thủy tinh đục nâu đen.

Các mắt trong nghiên cứu của chúng tôi là các mắt có độ cứng của nhân ở độ IV và $V$. Trong đó có 29 mắt nhân cứng độ IV $(85,3 \%)$ chỉ có 5 mắt có nhân cứng độ $\mathrm{V}(14,7 \%)$.

\section{Thị lực nhìn xa không chỉnh kính}

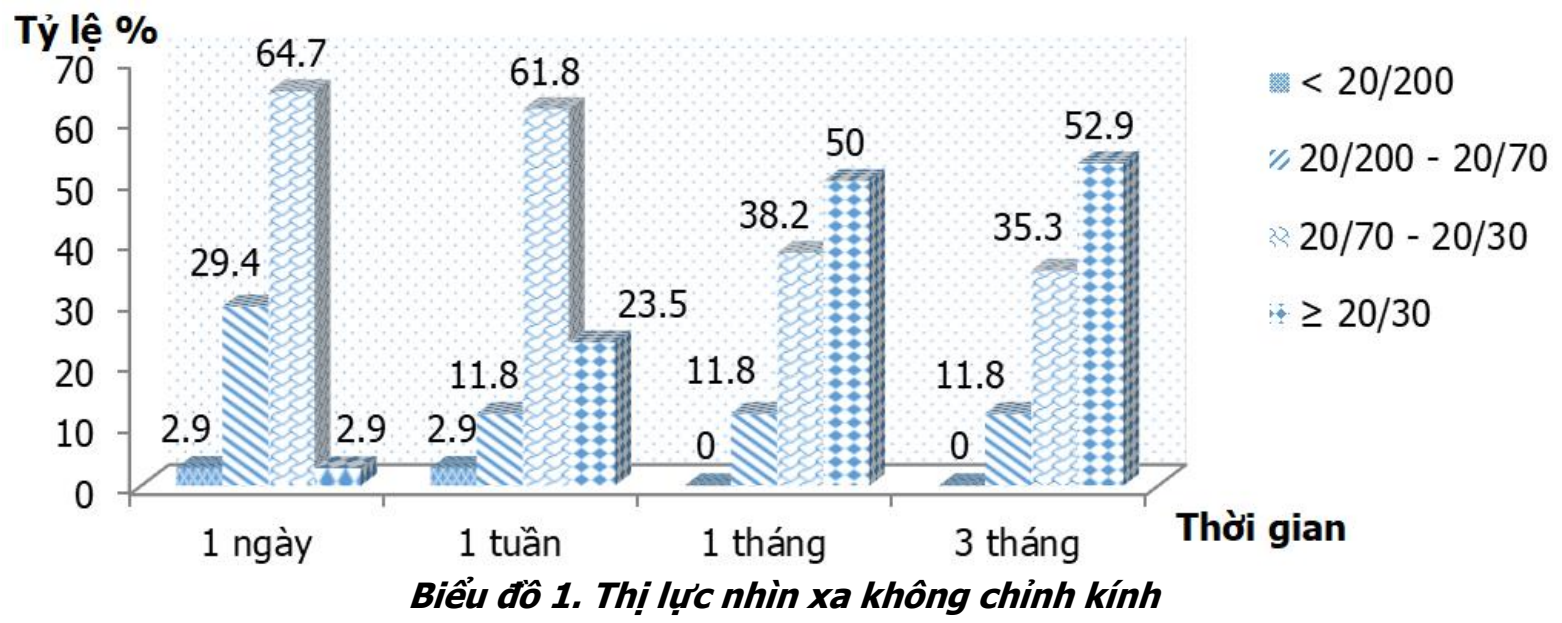

Thi lực của các bênh nhân trước mổ hầu hết là thấp, chủ yếu là thấp hơn ĐNT 3 mét $(67,6 \%)$, trong đó có 10 mắt có thi lực từ $\mathrm{ST}(+)$ đên ĐNT $1 \mathrm{~m}(29,4 \%)$. Trong nghiên cứu của các tác giả trước đây trên mắt đục TाT nâu đen như Nguyền Đố Nguyên (2007) trên 60 mắt đục TाT độ V, nghiên cứu của Trân Thị Phương Thu (2002) trên 50 mắt đục độ $\mathrm{V}$, nghiên cứu của Trần Phạm Duy (2012) trển 45 mắt đục TTT độ $V$, nghiên cứu của Đinh Thị Phương Thủy trên 50 mắt đục TाT độ IV và $V$ cho thấy thị lực của bênh nhân dưới ĐNT 1 $m$ chiếm tỉ lê từ $52 \%$ đến $63,3 \%$.

Thi lực của các mắt trong nghiên cứu đã cải thiên rõ rệt sau phẫu thuật, chỉ có 1 mắt có thi lực <20/200 sau 1 ngày. Đây là trường hợp 1 bệnh nhân nữ nhân đục độ $V$ và có thời gian phaco cao nhất trong nhóm nghiên cứu (89s). Có 23 mắt có thi lực $\geq 20 / 70$ sau 1 ngày $(64,7 \%)$. Kết quả này cũng tương đương với kết quả của tác giả Đinh Thị Phương Thủy $66 \%$ số mắt đat thi lực $\geq 20 / 70$ ngày thứ nhất sau mổ và nghiên cứu của trên 48 mắt đục TाT nhân cứng cho thấy sau phẫu thuâtt 1 tuần có $60,42 \%$ mắt đạt thị lực $\geq 20 / 70$. Tuy nhiên thấp hơn so với nghiên cứu của Trần Thị Phương Thu (2002) và Zeng $\mathrm{M}$ sau phẫu thuật 1 ngày có xấp xỉ $80 \%$ bệnh nhân có thị lực >20/40.

Sau 1 tuần, có 8 mắt có thị lực $\geq 20 / 30$ $(23,8 \%)$ và 21 mắt $(61,8 \%)$ có thị lực từ $20 / 70$ đến $<20 / 30$. Sau 1 tháng không còn mắt nào có thị lực < 20/200, có 17 mắt $(50 \%)$ có thị lực $\geq 20 / 30$. Sau 3 tháng có 18 mắt $(52,9 \%)$ có thị lực $\geq 20 / 30$.

Thị lực sau 1 tháng cải thiện rõ rệt so với thị lực của nhóm sau phẫu thuật 1 tuần với $\mathrm{p}<$ 0,05 . Không có sự khác biêt giữa thị lực của nhóm nghiên cứu sau 3 tháng và 1 tháng. Điều này cho thấy hâuu hết các bệnh nhân ổn định thị lực sau phẫu thuât 1 tháng. Sau 3 tháng, thị lực của các mắt phấu thuật ổn đinh và đạt thị lực trung bình là $20 / 35,1 \pm 20 / 95$. Kết quả này tương tự với thi lực trung bình trong nghiên cứu của S Ravindran ${ }^{5}$ với thi lực trung bình sau phẫu thuât 1 tháng trên bênh nhân có nhân nâu đen là $20 / 32,4 \pm 20 / 32,4$.

Đô loan thị. So sánh đô loạn thi trung bình trước mố $0,41 \pm 0,4 \mathrm{D}$ với đồ loạn thị trung bình sau mổ 1 tuần là $0,53 \pm 0,41 \mathrm{D}$ và 1 tháng 0,47 $\pm 0,42 \mathrm{D}$ thì sự khác biệt có ý nghĩa thống kê với p lần lượt là 0,004 và $0,046(<0,05)$. 
Bảng 1. Độ loạn thị sau phẫu thuật ở các thời điểm

\begin{tabular}{|c|c|c|c|c|c|c|}
\hline \multirow{2}{*}{ Độ loạn thị Thời gian } & \multicolumn{2}{|c|}{ Sau mố 1 tuân } & \multicolumn{2}{c|}{ Sau mố 1 tháng } & \multicolumn{2}{c|}{ Sau mố 3 tháng } \\
\cline { 2 - 7 } & $\mathbf{n}$ & $\mathbf{\%}$ & $\mathbf{n}$ & $\mathbf{\%}$ & $\mathbf{n}$ & $\mathbf{\%}$ \\
\hline $0,00-0,50$ & 27 & 79,4 & 28 & 82,4 & 28 & 82,4 \\
\hline $0,75-1,00$ & 4 & 11,8 & 3 & 8,8 & 3 & 8,8 \\
\hline $1,25-1,50$ & 2 & 5,9 & 2 & 5,9 & 2 & 5,9 \\
\hline $1,75-2,00$ & 1 & 2,9 & 1 & 2,9 & 1 & 5,9 \\
\hline Tống & $\mathbf{3 4}$ & $\mathbf{1 0 0}$ & $\mathbf{3 4}$ & $\mathbf{1 0 0}$ & $\mathbf{3 4}$ & $\mathbf{1 0 0}$ \\
\hline
\end{tabular}

Chúng tôi nhận thãy khi so sánh độ loạn thị trung bình trước mổ với độ loạn thị trung bình sau mổ 3 tháng thì lại không có sự khác biệt có ý nghĩa thống kê với $p=0,236(>0,05)$.

Điều đó cho thấy với đường rạch giác mạc 2,2mm không làm thay đổi độ loạn thị giác mạc đáng kể ở thời điểm 3 tháng khi đã ổn định. Thông thường loạn thị giác mạc tăng lên cao nhất vào những ngày đầu sau phẫu thuật sau đó giảm dần và ổn định sau 3 tháng.
Theo Đặng Ngọc Hoàng khi so sánh độ loạn trung bình ở các thời điểm 1 tuần, 1 tháng và 3 tháng thì sự khác biệt không có ý nghĩa thống kê với $p$ lần lượt là 0,$06 ; 0,06$ và 0,08 . Như vậy độ loạn thị giác mạc ở thời điểm 3 tháng tương đương với độ loạn thị trước phẫu thuật.

Thay đổi loạn thị do phẫu thuật. Sự thay đổi loạn thị do phấu thuật ở các thời điểm sau mổ so với trước mổ gồm có độ loạn thị giảm, độ loạn thị tăng và độ loạn thị khổng đổi.

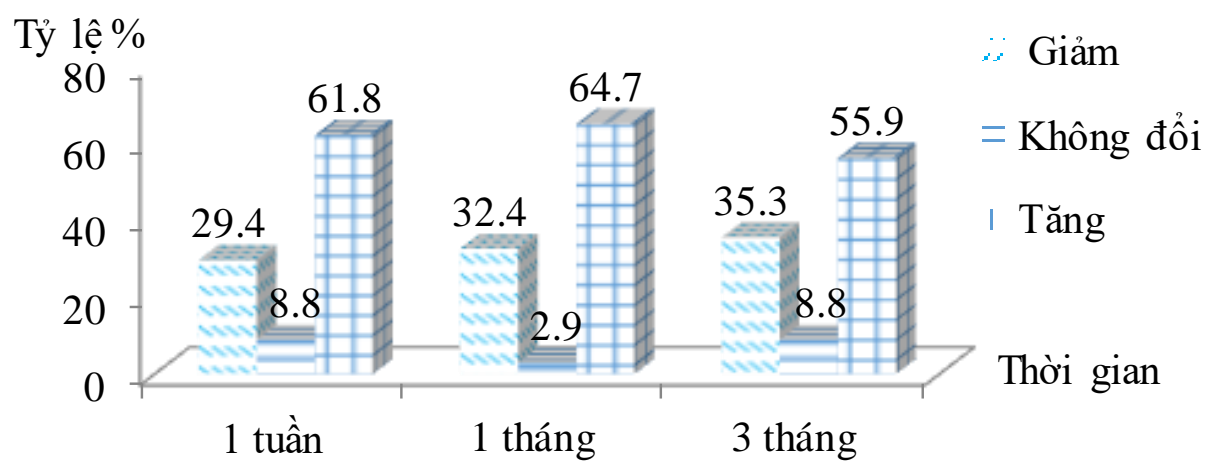

Biểu đồ 2. Thay đổi loạn thị do phẫu thuật

Độ loạn thị trung bình gây ra do phẫu thuật ở thời điểm 1 tuần là $0,20 \pm 0,11 \mathrm{D}$, trong đó có 4 trường hợp $(11,8 \%)$ có đô loạn thi gây ra do phẫu thuật bằng 0 có nghĩa là ở những trường hợp này đường rạch 2,2mm không gây ra biến đổi câu trúc của giác mạc, khúc xạ giác mạc không có thay đổi gì so với trước phẫu thuật.

Độ loạn thị trung bình gây ra do phẫu thuật ở thời điểm 1 tháng là $0,18 \pm 0,06 \mathrm{D}$ và 3 tháng là $0,17 \pm 0,09 \mathrm{D}$. Như vâyy thì độ loạn thị gây ra do phẫu thuật trong nghiên cứu giảm dân theo thời gian do giác mạc liền seeo và ổn định trở lại. So sánh với một số tác giả thấy độ loạn thị trung bình gây ra do phẫu thuật khi sử dụng đường rạch giác mạc 2,2mm đều ở mức < 0,5D như bảng 2 trình bày.

Bảng 2. Loan thị giác mạc trung bình gây ra do phấu thuật ở một số tác giả

\section{Tác giả}

\begin{tabular}{|c|c|c|c|}
\hline & 1 tuân & 1 tháng & 3 tháng \\
\hline Đă̆ng Ngọc $^{\text {Hoàng }}$ & $0,31 \pm$ & $0,29 \pm$ & $0,24 \pm$ \\
\hline Nguyền & 0,17 & 0,17 & 0,15 \\
Quốc Toản & & $0,28 \pm$ & $0,24 \pm$ \\
\hline Jun Wang & & 0,07 & 0,07 \\
\hline Nhóm & $0,20 \pm$ & $0,18 \pm 0,5$ & $0,4 \pm 0,2$ \\
nghiên cứu & 0,11 & 0,06 & $0,17 \pm$ \\
\hline
\end{tabular}

Những nghiên cứu trong và ngoài nước về vai trò của kích thước đường rạch giác mạc trong phẫu thuật phaco đã có cùng chung nhận xét là độ loạn thị gây ra do phẫu thuật chịu ảnh hưởng của kích thước đường rạch.

Zeng và cộng sự so sánh giữa phương pháp phẫu thuật ngoài bao đường rạch giác mạc $12 \mathrm{~mm}, 6 \mathrm{~mm}$ và phương pháp phaco với đường rạch giác mạc $3 \mathrm{~mm}$ tại 2 vị trí $12 \mathrm{~h}$ và vị trí phía thái dương thì sau theo dõi kết quả cho thây đường rạch giác mạc càng rộng thì loạn thị sau phẫu thuật càng lớn. Nhóm mổ bằng phương 
pháp phaco có đường rạch giác mạc vị trí thái dương có độ loạn thị sau mổ ít hơn nhóm có vị trí đường rạch giác mạc phía $12 \mathrm{~h}$..

Theo Jun Wang khi so sánh độ loạn thị giác mạc gây ra do phẩu thuật giữa đường rạch giác mạc $2,2 \mathrm{~mm}$ với đường rạch giác mạc $3,0 \mathrm{~mm}$ thì thấy độ loạn thị gây ra do phẫu thuật với kích thước đường rạch 2,2mm nhỏ hơn có ý nghĩa thống kê với $p \leq 0,015$ và ổn định theo thời gian.

4. Các khó khăn trong phẫu thuật Bảng 3. Khó khăn trong phẫu thuật

\begin{tabular}{|c|c|c|c|c|}
\hline $\begin{array}{c}\text { Khó } \\
\text { khăn } \\
\text { trong } \\
\text { mố }\end{array}$ & $\begin{array}{c}\text { Đồng } \\
\text { tử kém } \\
\text { giãn }\end{array}$ & $\begin{array}{c}\text { Đồng } \\
\text { tử co } \\
\text { nhỏ }\end{array}$ & $\begin{array}{c}\text { Dây } \\
\text { Zinn } \\
\text { yếu }\end{array}$ & $\begin{array}{c}\text { Tiền phòng } \\
\text { không ổn } \\
\text { định }\end{array}$ \\
\hline Số ca & 1 & 1 & 2 & 4 \\
\hline Tỷ lệ $\%$ & $2,9 \%$ & $2,9 \%$ & $5,9 \%$ & $11,8 \%$ \\
\hline
\end{tabular}

Trong nghiên cứu của chúng tôi có 1 trường hợp nhỏ giãn trước mổ $1 \mathrm{~h}$ nhưng kích thước đồng tử tối đa chỉ giãn được $5 \mathrm{~mm}$. Có 1 trường hợp đồng tử co nhỏ khi bắt đầu làm thì phaco. 2 trường hợp dây chằng Zinn yếu gặp ở bệnh nhân cao tuổi có nhân cứng độ $V$ và 4 trường hợp tiền phòng không ổn định trong phẫu thuật. Những khó khăn bao gồm đồng tử kém giãn, đồng tử co nhỏ, dây Zinn yếu cũng được coi là những khó khăn hay gặp phải trong phẫu thuật phaco trên những nhân cứng. ${ }^{2,3}$ Tuy nhiên trong nghiên cứu của Sigh không thấy có khó khăn nào đáng kể trong thì phaco

\section{Các biến chứng}

Biến chứng trong phẫu thuật. Trong nghiên cứu có hai trường hợp bỏng mép mổ gặp ở 2 mắt nhân cứng độ $\mathrm{V}$, iỗi nhân rắn và dẻo, đỉnh khó tách làm đôi, phải dừng lại 2 lần để thông tắc đầu phaco, thời gian phaco kéo dài. Một trường hợp rách bao sau ở cuối thì phaco xảy ra ở mắt dây chằng Zinn yếu, áp lực dịch kính võng mạc cao, tiền phòng nông và không ổn định. 2,3 Trong nghiên cứu của Singh có $13,1 \%$ số mắt có bỏng mép vết mổ, tuy nhiên tác giả không ghi nhận trường hợp các biến chứng khác trong phẫu thuât.

Biến chứng sau phẫu thuật

Bảng 4. Các biến chứng sau phẫu thuật

\begin{tabular}{|c|c|c|c|c|}
\hline $\begin{array}{c}\text { Biến } \\
\text { chứng } \\
\text { sau mổ }\end{array}$ & $\begin{array}{c}\text { Phù } \\
\text { giác } \\
\text { mạc }\end{array}$ & $\begin{array}{c}\text { Viêm } \\
\text { màng } \\
\text { bồ đào }\end{array}$ & $\begin{array}{c}\text { Lệch } \\
\text { IOL }\end{array}$ & $\begin{array}{c}\text { Đục } \\
\text { bao } \\
\text { sau }\end{array}$ \\
\hline Số ca & 2 & 1 & 0 & 1 \\
\hline Tỷ lệ $\%$ & $5,9 \%$ & $2,9 \%$ & $0 \%$ & $2,9 \%$ \\
\hline
\end{tabular}

Sau phẫu thuật 1 ngày có 2 trường hợp có phù giác mạc trung bình chủ yếu tại quanh vị trí mép vết mổ, 2 trường hợp này là 2 trường hợp có bỏng giác mạc tại vị trí mổ. Phù giác mạc xuất hiện sau phẫu thuật 1 ngày. Tuy nhiên sau 1 tuần khám lại giác mạc của cả 2 trường hợp đã trong trở lại. Trong nghiên cứu của chúng tôi có 1 trường hợp viêm màng bồ đào trước bán cấp sau phẫu thuật 1 tuần với xuất tiết mỏng diện đồng tử và trước IOL, được điều trị chống viêm và chống dính thì tình trạng đã cải thiện tốt sau 2 tuần dùng thuốc.

Tại thời điểm 3 tháng có 1 bệnh nhân đục bao sau mức độ trung bình, chúng tôi đã tiến hành laser bao sau.

Bệnh nhân trong nhóm nghiên cứu của chúng tôi có tỉ lệ đặt TाT trong bao và cân $100 \%$. Không ghi nhận có trường hợp nào TTTNT bị lệch trong các thời điểm tái khám.

\section{KẾT LUÂN}

Phẫu thuật Phaco nhân nâu đen qua đường rạch giác mạc $2.2 \mathrm{~mm}$ mặc dù có một số khó khăn, thời gian phaco kéo dài hơn khi nhân thể thủy tinh cứng tuy nhiên đây vẫn là phương pháp an toàn, hiệu quả, tỷ lệ thành công của phẫu thuật cao, độ loạn thị gây ra do phẫu thuật thấp và ổn định sau khoảng 1 tháng phẫu thuật.

\section{TÀI LIÊU THAM KHẢO}

1. Zheng $\mathbf{D}$, Liu $\mathbf{Y}$. [Observation of complications at the operative and early postoperative stages of phacoemulsification]. Yan Ke Xue Bao. 1998; 14(2): 105-107, 104.

2. Đinh Thị Phương Thủy. Đánh giá kết quả điều trị đục thể thủy tinh nhân nâu đen bằng phương pháp Phaco, Luận văn thạc sỹ y học, Trương Đại học Y Hà Nối. 2013.

3. Nguyến Đố Nguyên (2007). Nghiên cứu phẫu thuật đục thể thủy tinh nhân nâu đen bằng phương pháp phaco chop cải biên. $Y$ học Thành Phố Hồ Chí Minh, 11, 233-239.

4. Ilavska M, Kardos $L$. Phacoemulsification of mature and hard nuclear cataracts. Bratisl Lek Listy. 2010;111(2):93-96.

5. Ravindran $S$, Aswin $P$, Shekhar $M$, Rajendran J, Narendran $\mathbf{S}$ Ravindran $\mathbf{R}$ Phacoemulsification versus manual-small incision cataract surgery for brunescent cataracts: A retrospective analysis. TNOA J Ophthalmic Sci Res. 2020;58(2):74. doi:10.4103/tjosr.tjosr_108_19

6. Đăng Ngọc Hoàng (2012). Nghiện Cứu Đánh Giá Kết Quả Phẫu Thuật Tán Nhuyễn Thủy Tinh Thể Với Đường Rach Giác Mac 2,2mm, Luận Văn Thạc Sỹ y Học, Trường Đại Học Y Hà Nội.

7. Wang J, Zhang E-K, Fan W-Y, Ma J-X, Zhao P-F. The effect of micro-incision and small-incision coaxial phaco-emulsification on corneal astigmatism. Clin Experiment Ophthalmol. 2009;37(7):664-669. doi:10.1111/j.1442$90712009.02117 x$

8. Zeng $\mathbf{Y}$, Gao J. Continuous Curvilinear Capsulorhexis in Cataract Surgery Using a Modified 3-Bend Cystotome. J Ophthalmol. 2015;2015:1-5. doi: $10.1155 / 2015 / 412810$ 